\title{
TRANSIÇÃO AGROECOLÓGICA E O PAPEL DA EXTENSÃO RURAL
}

\author{
Francisco Roberto Caporal ${ }^{1}$
}

\begin{abstract}
RESUMO
Este texto situa o papel da extensão rural no marco de novas iniciativas de desenvolvimento rural que devem ser orientadas pelo imperativo socioambiental. Destaca-se que os processos de transição agroecológica devem sustentar-se nos conceitos e princípios da Agroecologia, razão pela qual buscou-se trazer uma aproximação a esses conceitos, bem como sobre as abordagens que tratam dos níveis de transição que devem orientar as ações dos extensionistas, agricultores ou consumidores envolvidos em processos. Neste sentido, considera-se que os processos de transição agroecológica requerem o apoio de uma Extensão Rural Agroecológica, que supere o modelo difusionista clássico do extensionismo rural e no qual o extensionista além do seu papel como técnico deve atuar como um facilitador. Ademais, sugere-se um conjunto de etapas da transição agroecológica, que vão da dimensão pessoal às dimensões meso e macrossocial, de modo que, na medida em que avança, o processo de transição se torna mais complexo, pois, a cada etapa correspondem novas propriedades emergentes. Portanto, a transição agroecológica não se confunde com a conversão para sistemas orgânicos pela simples substituição de insumos. O objetivo deste artigo é, justamente, refletir sobre a complexidade dos processos de transição agroecológica e sobre o papel que pode desempenhar a extensão rural.
\end{abstract}

Palavras-chave: Agroecologia, desenvolvimento rural, extensão rural Agroecológica, extensão rural, transição social Agroecológica.

\section{AGRICULTURAL TRANSITION AND THE ROLE OF RURAL EXTENSION}

\begin{abstract}
This text places the role of rural extension in the framework of new rural development initiatives that must be guided by the socio-environmental imperative. It is noteworthy that the agroecological transition processes must be based on the concepts and principles of Agroecology, which is why we sought to bring these concepts closer together, as well as on the approaches that deal with the levels of transition that should guide the actions of the extension workers, farmers or consumers involved in processes. In this sense, it is considered that the agroecological transition processes require the support of an Agroecological Rural Extension, which surpasses the classic diffusionist model of rural extensionism and in which the extensionist, in addition to his role as a technician, should act as a facilitator. In addition, a set of stages of the agroecological transition is suggested, ranging from the personal dimension to the

1 Graduado em Agronomia (UFSM). Mestrado em Extensão Rural (UFSM). Doutorado em Agroecologia e Campesinato (ISEC-Universidade de Córdoba-Espanha). Professor da Universidade Federal Rural de Pernambuco (UFRPE). E-mail: caporalfr@gmail.com.
\end{abstract}


meso and macrosocial dimensions, so that, as it progresses, the transition process becomes more complex, as each stage corresponds to new ones emerging properties. Therefore, the agroecological transition is not to be confused with the conversion to organic systems by the simple substitution of inputs. The purpose of this article is, precisely, to reflect on the complexity of the agroecological transition processes and on the role that rural extension can play.

Keywords: Agroecology, rural development, Agroecological rural extension, rural extension, Agroecological social transition.

\section{INTRODUÇÃO}

O imperativo socioambiental, como resposta à crise civilizatória em que nos encontramos, exige novas políticas públicas para o desenvolvimento rural. Logo, diante do desafio de apoiar estratégias que se orientem pela sustentabilidade socioambiental, torna-se indispensável a oferta estatal de serviços de Assistência Técnica e Extensão Rural (ATER) imbuídos do propósito de contribuir para uma ampla transição agroecológica, visando a construção de sistemas agrícolas e agroalimentares ecologicamente mais sustentáveis, resilientes e socialmente mais includentes.

Como é sabido, abunda a bibliografia (GRAZIANO DA SILVA, 1982; CAPORAL, 1998; SARANDON, 2002) que analisa os equívocos da Revolução Verde e as consequências indesejáveis do modelo de difusão de tecnologias que orientou a prática extensionista, com base na Teoria da Difusão de Inovações. Está cada vez mais claro que o modelo de extensão rural baseado no difusionismo é incapaz de contribuir para que se encontrem respostas para a atual crise socioambiental. Do mesmo modo, a trajetória da maioria dos aparatos de extensão rural públicos e privados, nos últimos anos, mostra que estamos longe de alcançar uma ação extensionista que seja transformadora, capaz de incluir os excluídos do campo, minimizar a pobreza rural e apoiar a busca de sustentabilidade ambiental nos processos de desenvolvimento rural.

Assim, neste texto, vamos iniciar tratando sobre transição agroecológica ou transições agroecológicas. Entretanto, isso determina a necessidade de começar explicitando os conceitos de Agroecologia que nos orientam nesta reflexão, pois é a partir destes conceitos que se delimitam os processos de transição. Do mesmo modo, trataremos sobre os conceitos de transição agroecológica, ou níveis da transição que devem orientar a busca de agriculturas e sistemas agroalimentares mais sustentáveis.

Ademais, como apoio a estes processos de transição, destacamos o papel que pode cumprir a extensão rural, que definimos como Extensão Rural Agroecológica (ERA), no capítulo VIII de nossa tese de doutorado (CAPORAL, 1998). Ou seja, um modelo que supere o difusionismo, e que possa contribuir, de fato, como ação animadora e incentivadora de processos de transição que não são simplesmente técnico-agronômicos, mas que precisam ser capazes de apoiar transformações no sentido da sustentabilidade e do bem viver dos sujeitos envolvidos.

Embora o conceito de ERA possa parecer antigo e que foi incorporado na Política Nacional de Assistência Técnica e Extensão Rural de 2004, é necessário continuar insistindo sobre o tema, pois, como se sabe, das discussões posteriores, esta prática educativa, democrática, participativa e agroecológica ainda não se consolidou como modelo adotado pela maioria das organizações de Ater.

Como afirmam Otero e Selis (2019, p. 21), a Extensão Rural: 
debe servir a la concientización y construcción de sujetos políticos que busquen transformar las relaciones de opresión en los espacios rurales. Sin embargo, asimismo, es preciso asumir una perspectiva cultural del asunto. En ese sentido, es imprescindible partir del reconocimiento del otro y entender al encuentro que se produce en la ER, como un espacio de diálogo y negociación por el significado de la experiencia, de la vida y del mundo.

Por último, realizamos uma aproximação a um "modelo" de transição agroecológica, que supõe várias etapas, que vão da dimensão pessoal às dimensões meso e macrossocial, nas quais os agentes de Extensão Rural Agroecológica deveriam estar implicados.

\section{SOBRE ALGUNS CONCEITOS DE AGROECOLOGICA E DE TRANSIÇÃO AGROECOLÓGICA}

Para os objetivos deste artigo vamos tomar como referência conceitos que nos parecem importantes, embora tenhamos claro que com eles não esgotamos o debate conceitual extenso que está presente neste campo de estudos. Para iniciar, tomamos os aportes de Sevilla Guzmán (1995, p. 6), para quem a "Agroecologia é uma disciplina científica que enfoca o estudo da agricultura desde uma perspectiva ecológica" [Tradução livre]. O autor, afirmar que:

[...] a Agroecologia pretende o manejo ecológico dos recursos naturais, para, através de um enfoque holístico e mediante a aplicação de uma estratégia sistêmica, reconduzir o curso alterado da coevolução social e ecológica, através do controle das forças produtivas que bloqueie seletivamente as formas degradantes e exploradoras, da produção e do consumo, causadores da atual crise ecológica. Em tal estratégia joga um papel central a dimensão local como portadora de um potencial endógeno que, através do conhecimento camponês, permita a potencialização da biodiversidade ecológica e sociocultural mediante o desenho de sistemas alternativos de agricultura sustentável" (SEVILLA GUZMÁN, 1995. p. 8). [Tradução livre]

Como é possível observar no conceito acima, o que se busca com o enfoque agroecológico são condições de mais sustentabilidade socioambiental, portanto, os processos de transição agroecológica se caracterizam pela passagem de formas mais degradantes de agricultura e de sistemas agroalimentares insustentáveis para estilos de agriculturas e sistemas agroalimentares mais sustentáveis. Entendendo, aqui, a sustentabilidade como a capacidade dos sistemas agrícolas e agroalimentares se manterem produtivos e sustentáveis no curto, médio e longo prazos. Isto é, preservando a base de recursos dos quais dependem as atuais e as futuras gerações.

Ademais, o conceito acima explicita a importância tanto do saber local como do potencial endógeno dos agroecossistemas, razão pela qual os agroecólogos precisam adotar metodologias participativas (do tipo investigação-ação participativa), o que determina a necessidade de que estejam implicados nos processos, de modo que, em conjunto com agricultores, façam uma detalhada leitura e diagnóstico dos agroecossistemas e dos sistemas agroalimentares, antes de estabelecerem as formas de manejo, as tecnologias/técnicas que deverão ser utilizadas, assim como os possíveis desenhos de sistemas produtivos mais sustentáveis, compatíveis com os recursos endógenos de cada agroecossistema. Do mesmo modo, devem ser 
participativas as etapas de planejamento e estabelecimento dos circuitos de comercialização e consumo.

Por isso, as transições agroecológicas (COSTABEBER et al. 2013) serão duplamente influídas. Por um lado, pelas condições específicas de cada lugar e, por outro, pelos elementos de cultura, pelos valores e normas sociais que orientam as pessoas e os grupos sociais responsáveis pelo manejo destes agroecossistemas e pelos circuitos de comercialização e consumo. Desta forma, a aplicação dos princípios da Agroecologia não permite a adoção de "pacotes verdes".

Sendo assim, os processos de transição nos levarão a tantos tipos de agriculturas quantos sejam os arranjos determinados por elementos da cultura local dos diferentes grupos sociais envolvidos e das variedades de agroecossistemas nos quais se esteja trabalhando. Isto é, há um processo de coevolução no qual as condições ecológicas influem nas decisões dos agricultores e grupos, assim como os elementos da cultura local influirão nas formas de manejo dos recursos naturais e nas formas de organização social. Estas, por sua vez, contribuirão (ou não) para o enfrentamento dos sistemas convencionais de circulação e consumo.

A transição agroecológica, portanto, é um processo multilinear, social e ecologicamente determinado, que não poderá ter um fim, uma vez que as formas de manejo e as formas organizativas serão dinâmicas ao longo do tempo. Logo, a transição tem que ser entendida com um processo permanente que, inclusive, vai continuar de geração em geração, com as adaptações e redesenhos que se fizerem necessários em cada momento. Por isso mesmo, no campo da produção agropecuária a transição agroecológica se diferencia da conversão para a agricultura orgânica, já que esta última supõe um tempo definido, muitas vezes estabelecido em normativas legais.

Voltando aos conceitos de Agroecologia, que orientam esta nossa reflexão, vamos tomar agora os aportes mais recentes de Stephen Gliessman (2016) sobre as transições. Para este autor, "a Agroecologia é uma forma de redesenhar os sistemas alimentares, do campo à mesa, (grifo nosso) com o objetivo de alcançar a sustentabilidade ecológica, econômica e social." [Tradução livre]

Relembrando Gliessman, historicamente, definia a Agroecologia como a ciência que oferece as bases ecológicas para a análise, manejo e desenho de agroecossistemas sustentáveis. Ou seja, Gliessman tratava da Agroecologia em nível de área de produção, de área da propriedade, o que tinha como unidade de análise o agroecossistema. Não obstante, dadas as novas configurações do campo agroecológico, o autor passou a incluir a necessidade de análise, também, de todo o sistema agroalimentar. Outros autores, igualmente, passaram a adotar esta nova perspectiva, na medida em que foram se dando conta de que o agroecossistema é um subsistema aninhado em outros subsistemas mais amplos e que está sofrendo influências destes outros subsistemas, influências que podem ser de natureza econômica, política, ambiental, cultural, etc. e são subsistemas do sistema agroalimentar.

Logo, Gliessman (2000), que apresentava e sugeria três níveis da transição agroecológica, agora incluiu outros dois níveis que se fizeram necessários para dar conta do novo e ampliado campo da Agroecologia. Vejamos, de forma resumida, como o autor apresenta os cinco níveis da transição agroecológica:

Nível 1: Aumentar a eficiência das práticas industriais e convencionais para reduzir o uso e consumo de insumos caros, escassos e prejudiciais ao meio ambiente. O primeiro objetivo de mudança desse nível é usar insumos industriais mais eficientes para que poucos insumos sejam necessários e seus 
impactos negativos também sejam reduzidos. A chamada "agricultura de precisão" é um foco recente de pesquisa no Nível 1.

Nível 2: Substituir insumos e práticas industriais / convencionais por práticas alternativas. O objetivo deste nível de transição é substituir os produtos e práticas externos intensivos em insumos e ambientalmente degradantes por aqueles que são mais renováveis, baseados em produtos naturais e mais ambientalmente saudáveis. Agricultura orgânica e agricultura biodinâmica são exemplos desta abordagem. No entanto, neste nível, o agroecossistema básico geralmente não é alterado de sua forma mais simplificada, portanto muitos dos mesmos problemas que ocorrem em sistemas industriais também ocorrem naqueles com substituição de insumos.

Nível 3: Redesenhar o agroecossistema para que ele funcione com base em um novo conjunto de processos ecológicos. Neste nível, mudanças fundamentais na concepção geral do sistema eliminam as causas de muitos dos problemas que continuam a persistir nos Níveis 1 e 2 . O foco está na prevenção de problemas antes que eles ocorram, ao invés de tentar controlálos depois que eles acontecem. Neste nível, a estrutura e função do agroecossistema são melhor compreendidas, e podem ser implementadas mudanças apropriadas no desenho. Os problemas são reconhecidos, os ajustes feitos nas abordagens internas de projeto e gerenciamento de espaço e tempo, em vez de apenas pelas aplicações de insumos externos. Um bom exemplo é a reintrodução da biodiversidade na estrutura e gestão da propriedade por meio de ações como rotações de base ecológica, cultivo múltiplo, agroflorestas e integração de animais com culturas. (GLIESSMAN, 2000, 2016) [Tradução livre]

Mais recentemente, Gliessman, adotando um enfoque mais complexo sobre as contribuições que a Agroecologia pode trazer para o campo da sustentabilidade socioambiental, propõe outros dois níveis da transição que passaram a ser indispensáveis para se transitar na direção de mais sustentabilidade. Vejamos:

Nível 4: Reestabelecer uma conexão mais direta entre aqueles que cultivam nossa comida e aqueles que a consomem. A transformação do sistema alimentar ocorre em um contexto cultural e econômico, e essa transformação deve promover a transição para práticas mais sustentáveis. Em nível local, isso significa que aqueles que comem devem valorizar os alimentos que são cultivados e processados localmente e apoiar os agricultores que estão tentando passar pelos níveis 1 a 3 . Este apoio torna-se uma espécie de "cidadania alimentar" e pode ser visto como uma força para a mudança do sistema alimentar. Comunidades de produtores e consumidores podem formar redes de alimentos alternativos em todo o mundo, onde uma nova cultura e uma nova economia da sustentabilidade do sistema alimentar estão sendo construídas. A comida, mais uma vez, deve ser fundamentada em relacionamentos diretos. Um exemplo importante é o atual movimento de relocalização dos alimentos, com as suas crescentes redes de mercados de agricultores, estratégias de produção apoiadas pela comunidade, cooperativas de consumo e outros acordos de comercialização, mais diretos, que encurtam a cadeia alimentar. 
Nível 5: Sobre a base criada pelos agroecossistemas sustentáveis em escala agropecuária alcançada no Nível 3 e as novas relações de sustentabilidade do Nível 4, construir um novo sistema alimentar global, baseado na equidade, participação, democracia e justiça, que não seja apenas sustentável, mas que ajude a restaurar e proteger os sistemas de apoio à vida da Terra dos quais todos dependemos. Ao pensar além dos Níveis 1 a 4 , o Nível 5 envolve mudanças que são globais em alcance e que vão além do sistema alimentar, envolvendo a natureza da cultura humana, [...]. A profundidade da mudança é mais do que uma simples conversão ou transição, e entra no reino da reforma ou transformação completa. Com nível de pensamento e ação de nível 5, a Agroecologia fornece maneiras de construir sobre os processos de mudança em escala de unidade de produção e de agricultor, para uma reflexão completa de como todos nós nos relacionamos uns com os outros e com a terra que nos apoia. Crenças básicas, valores e sistemas éticos mudam. (GLIESSMAN, 2016) [Tradução livre]

Esta longa citação se justifica na medida em que ela nos traz novos caminhos para a transição, muito mais complexos do que simplesmente fazer mudanças nas práticas agrícolas e formas de manejo no nível local de cada agroecossistema. Neste sentido, Eduardo Sevilla Guzmán et. al (2012) já haviam sentenciado que a Agroecologia e a transição agroecológica podem ser melhor entendidas se observarmos as três dimensões da Agroecologia, que os autores assim definem:

\begin{abstract}
A primeira dimensão da Agroecologia é a ecológica e técnicoprodutiva centrada no desenho dos agroecossistemas, sendo a ecologia o marco científico de referência que, em diálogo com o conhecimento tradicional campesino e indígena propõe a redefinição dos fundamentos técnicos da agronomia, da veterinária e das ciências florestais. A segunda dimensão, a socioeconômica, se caracteriza por um forte conteúdo endógeno, prioritariamente através da análise de das sociedades locais, das estratégias produtivas e dos processos de desenvolvimento rural. Finalmente, a dimensão política da Agroecologia se traduz na implicação prática, na construção de alternativas à globalização agroalimentar, mediante o apoio e acompanhamento de ações coletivas, tanto produtivas ou de comercialização como de luta política. Nesta última dimensão a Agroecologia se articula com a proposta política da Soberania Alimentar (SEVILLA GUZMÁN et al., 2012, p. 37) [Tradução libre]
\end{abstract}

Como é possível observar, os autores avançam para uma questão chave que é a necessidade da ação social coletiva. Esta noção implica em formas organizativas diferenciadas, em cooperação, em ajuda mútua. Ademais, como em Gliessman, acima citado, não se trata somente de agir nos processos de produção, mas também nas formas de distribuição, comercialização e consumo. E acrescentaríamos: reciclagem e descarte.

Por último, cabe destacar que nesta seção não se pretendeu fazer uma revisão bibliográfica profunda sobre o tema, mas sim destacar elementos e passos fundamentais dos processos de transição agroecológica, que são complexos em qualquer das escalas antes mencionadas, do local ao global, e que, portanto, se requer uma metodologia adequada para as ações de transição e um apoio de políticas públicas, entre as quais destacamos a extensão rural. 


\section{OS PROCESSOS (“MODELO") DE TRANSIÇÃO AGREOCOLÓGICA: NÍVEIS DE INOVAÇÕES SOCIOTÉCNICAS}

Para a abordagem de processos de transição tomaremos como referência dois textos básicos, um deles publicado pelos colegas Calle Collado e Gallar (2010) e outro de Calle Collado; Gallar e Candón (2013). Nestes textos, os autores fazem uma abordagem a partir da Agroecologia Política, para chegarem a uma proposta metodológica que contribui para melhor se entender os processos de transição agroecológica a partir de quatro grandes dimensões: a) dimensão pessoal; b) dimensão micro-social; c) dimensão eco-estrutural; e, d) dimensão meso e macrossocial.

O âmbito da dimensão pessoal, a que os autores se referem, seria o espaço de construção de "credibilidade e motivação", que nascem da tomada de "consciência" dos indivíduos e grupos implicados na transição em nível de unidade de produção, de comunidade ou território.

Já, a dimensão microsocial é o espaço da transição em que se dá a cooperação social, o associativismo, o apoio mútuo, a construção de redes de confiança entre produtores e entre produtores e consumidores, gerando espaços de autonomia. Estas novas relações, ou seja, estas micro democracias, por sua vez, estimulariam e dariam mais solidez e permanência às mudanças na dimensão pessoal. Deve-se observar que a cooperação é uma condição fundamental, pois sem a cooperação a pequena agricultura familiar ou camponesa não poderá competir com os médios e grandes produtores que já estão fazendo conversão da agricultura convencional para a agricultura orgânica. $E$ isto porque os médios e grandes produtores que fizerem a conversão terão muito mais recursos financeiros e naturais, maior escala e mais competitividade para disputar mercados, além de terem melhores condições para fechar ciclos, como o de matéria orgânica, por exemplo, na medida em que dispõe de maiores áreas.

Por outro lado, na dimensão microssocial é onde se constroem os espaços que os autores chamam de "democracia radical", ou seja, espaços de autogestão, de decisões coletivas, que também ajudam a fortalecer a consciência para a transformação. Nessa dimensão microssocial, também se dariam os processos de intercâmbio de conhecimentos nas relações agricultor-agricultor e de construção de novos conhecimentos agroecológicos, localmente adaptados, a partir da integração dos saberes camponeses, saberes tradicionais, com os conhecimentos científicos.

Por sua vez, na dimensão eco-estrutural a transição se concretiza por diferentes caminhos, todos eles inter-relacionados e complementares. Nesta dimensão se construirão os processos produtivos de base ecológica, potencializados pelos recursos endógenos dos territórios, e ancorados na biodiversidade sociocultural, que seriam as bases para a sustentabilidade dos Sistemas Agroalimentares Localizados de Base Agroecológica (SALBA), uma expressão concreta dos circuitos curtos de comercialização e consumo. Nesta dimensão, deve-se ter em mente a necessidade de fechamento de "circuitos de circulação" e de ciclos de matéria e de energia. Portanto, aqui, o enfoque territorial e a cooperação serão fundamentais. Um exemplo claro e objetivo é o fechamento do ciclo de matéria orgânica que, na maioria das vezes, é impossível realizar-se em nível de unidade de produção, como vimos, especialmente nas pequenas propriedades.

Não obstante, cabe ressaltar que tudo isso depende dos avanços da transição na dimensão microssocial, pois, repetimos, será a cooperação social a mola impulsora dos processos nesta dimensão. Deste modo, espera-se que a transição nesta dimensão promova a segurança e a soberania alimentar. Por outro lado, todos estes processos são alimentados, cuidados e protegidos pelas dimensões um e dois. 
Por fim, é na dimensão meso e macrossocial, onde se daria a construção de instituições sociais capazes de dar suporte a todas as dimensões anteriores. Como se trata de um processo em espiral, sua base e sua força nascem das três dimensões anteriores, especialmente, a partir das experiências de cooperação social. Do ponto de vista prático, a dimensão meso e macrossocial se constituiria no espaço de lutas e disputas por políticas públicas e por legislações e normas que favoreçam e fortaleçam as transições agroecológicas. (CALLE COLLADO; GALLAR; CANDÓN, 2013, p. 2556). Ademais, também seria o lugar das instituições sociais populares de suporte às dimensões anteriores, como, por exemplo, os bancos de sementes e raças, as trocas de mudas florestais, ou instituições públicas e ONGs responsáveis pela oferta de serviços de Extensão Rural Agroecológica.

Fortalecido pelas dimensões anteriores, aqui seria também o espaço das disputas por leis e programas que garantam o acesso a recursos como terra e água, pela mudança das leis que limitam processos de transição (leis de sementes, crédito rural, agroindústria, etc). Esses novos marcos normativos poderiam servir como estímulo para a entrada de atores sociais no campo da dimensão pessoal, retomando o circuito virtuoso de inovações sociotécnicas.

O conjunto destas quatro dimensões, constituem um "modelo de transição agroecológica, com produção positiva de inovações" (CALLE COLLADO; GALLAR, 2010, p. 8). Como se pode ver a seguir (Figura 1), o modelo é dinâmico e busca interrelacionar as quatro dimensões antes mencionadas. As dimensões seriam a "espinha dorsal para a análise da transição agroecológica" e essa, por sua vez, deveria estar sustentada por inovações positivas, em uma espiral crescente. Os autores afirmam que usam a adjetivação de "positivas" para indicar que elas devem ser produzidas no sentido contrário àquelas impostas pelos impérios agroalimentares, pelos sistemas agroalimentares dominados por grandes grupos nacionais ou transnacionais. Ou seja, contra a "destruição de cooperação social", contra o "alongamento dos circuitos" de comercialização que favorecem a acumulação capitalista a favor de grandes redes comerciais, contra as "suas propostas de revoluções verdes modernizantes" e contra a dominação e exclusão social que são próprios dos mercados globalizados (CALLE COLLADO; GALLAR, 2010, p.8).

Ademais, os mesmos autores esclarecem que "inovações sociais são aquelas relacionadas às novas formas de fazer, pensar, sentir". Seriam aquelas inovações "que constituirão estilos alimentares emergentes", da produção ao consumo. Isso pode ocorrer mediante a visibilização de práticas, formas produção e de organização já existentes, por exemplo, entre diferentes grupos sociais camponeses e consumidores conscientes, ou mesmo através da recuperação de saberes tradicionais, o que supõe, na prática, a proposta agroecológica de diálogo entre estes saberes e os conhecimentos científicos (CALLE COLLADO; GALLAR, 2010, p. 9). 
Figura 1 - Circuito virtuoso de inovações sociotécnicas para a transição agroecológica.

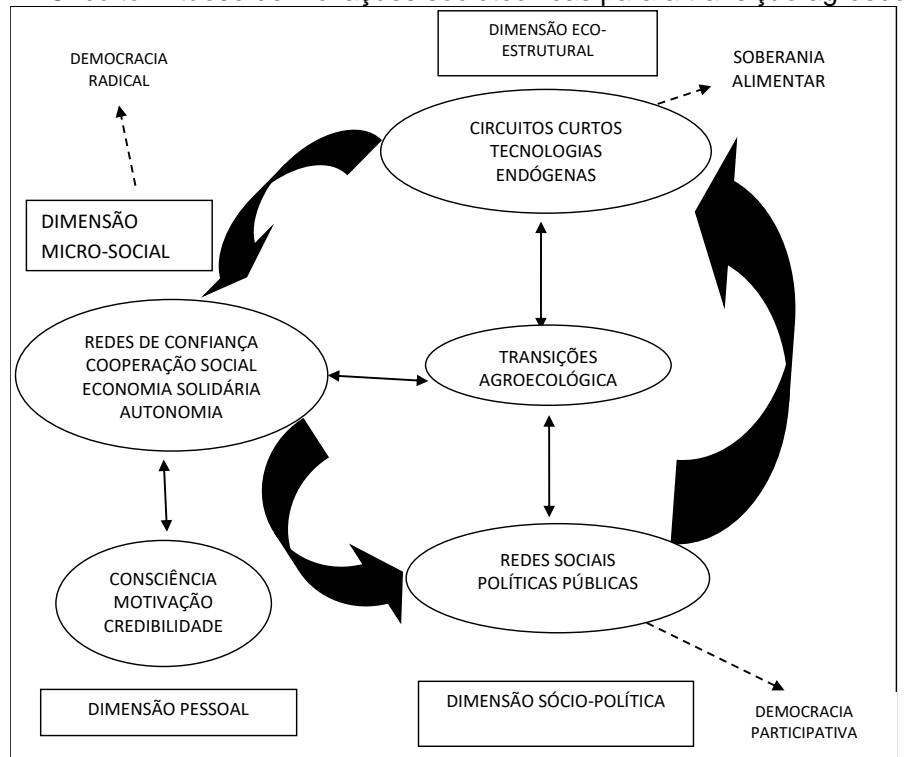

Fonte: Adaptado de Calle Collado; Gallar (2010); Calle Collado; Gallar; Cadón (2013).

Com a figura se pretende explicitar a necessidade de uma sequência de "giros positivos" com inovações sociais em cada uma das quatro dimensões, cada uma retroalimentando as demais, dando sequência ao processo de transição nos diferentes níveis ou dimensões. Vejamos como pode ser detalhada a dinâmica expressa no gráfico.

Esta sequência de giros positivos começa pela tomada de consciência e segue a partir da cooperação. Ambos estimulam a adoção de tecnologias endógenas e geram a capacidade de criar circuitos curtos de comercialização e consumo. Se trataria de construir, reconstruir ou fortalecer Sistemas Agroalimentares Localizados de Base Agroecológica (em nível de comunidades e territórios, por exemplo), envolvendo vários setores e diferentes atores sociais individuais e coletivos, incluindo os consumidores engajados nos processos e comprometidos com as mudanças desejadas em direção à sustentabilidade socioambiental, mas também em direção à autonomia dos agricultores. Isso implicaria em práticas de economia solidária, cooperativas ou associações de produtores e consumidores, etc. Ou seja, "a cooperação social é uma base e ao mesmo tempo um fato intrínseco dos processos de transição agroecológica" (CALLE COLLADO; GALLAR, 2010, p. 9) [Tradução livre] Acrescentaríamos: intrínseco e indispensável para assegurar a transição.

Para os autores acima citados,

Estas formas de cooperação social, em um contexto favorável de circuitos curtos e tecnologias endógenas, são as que podem produzir maior motivação para a implicação na mudança social agroecológica, porque são os garantidores de segurança e confiança sobre a satisfação das necessidades básicas: acesso aos recursos produtivos ou econômicos; redes de apoio e trocas que facilitem uma produção diversificada a partir de manejos agroecológicos, de menos dependência ou custo econômico; 
resiliência social ante as adversidades naturais ou diretamente derivadas dos impérios agroalimentares; maior autonomia em geral e na tomada de decisões; possibilidade de desenhar coletivamente estratégias comerciais ou de inovações sociais e tecnológicas; (CALLE COLLADO; GALLAR, 2010, p.10) [Tradução livre]

Não obstante, como expressa a figura, estes "giros positivos", em uma espiral crescente, requerem uma continuidade em cada uma das dimensões, pois, como vimos antes, a transição é um processo multidimensional mediante o qual vão sendo construídos caminhos novos e vão se estabelecendo novas bases socioecológias sobre as quais irá acontecendo a sequência da transição, já em novos patamares. Portanto, é fundamental que as dimensões avancem de forma equilibrada, num processo permanente de retroalimentação. Ou seja, avançando a cada degrau para níveis de maior sustentabilidade social, econômica, política, institucional, com mais justiça social, com mais equidade de gênero, com maiores níveis de resiliência, maiores níveis de independência e de autonomia.

Como fica claro na figura, a transição requer o aprofundamento da democracia participativa e, ao mesmo tempo, a realimenta. Do mesmo modo, podese pensar que no interior deste movimento de giros positivos, de cooperação e de autogestão se vai avançando no sentido de mais horizontalidade nas relações sociais e afetivas, em novas relações com a natureza, em novos processos de participação deliberativa que alimentam um avanço para uma democracia radical entre os grupos e atores envolvidos. Estas são condições importantes para a construção dos Sistemas Agroalimentares Localizados de Base Agroecológica a que nos referimos antes. Portanto, as ações em cada uma das dimensões realimentam as outras e todas elas dão passo a processos contínuos e permanentes de transição agroecológica.

\section{SOBRE O PAPEL DA EXTENSÃO RURAL AGROECOLÓGICA}

Os cenários atuais, num ambiente de múltiplas crises, sugere que as ações de ATER, em especial do setor público, necessitam reinventar-se (não apenas trocar de roupa), de modo que os agentes possam passar a atuar pautados pelo uso de metodologias participativas e por um enfoque agroecológico, assumindo o papel de facilitadores de processos de transição agroecológica, fortalecendo o potencial endógeno dos territórios, comunidades ou agroecossistemas e estimulando práticas inovadoras e sustentáveis nos processos de distribuição, transformação e consumo dos produtos.

Ao contrário da prática convencional difusionista de pacotes, a extensão rural para ser contemporânea requer uma ação que parta do conhecimento e análise dos agroecossistemas e dos sistemas agroalimentares, estimulando alternativas baseadas em princípios que aproximem a Agronomia da Ecologia a partir de um enfoque holístico e sistêmico. Neste sentido, o conceito de Extensão Rural Agroecológica pode ser um indicativo dos rumos de uma prática extensionista distinta e comprometida com a agricultura familiar camponesa e com as demandas socioambientais e por equidade social que são inquestionáveis atualmente. A velha institucionalidade da extensão rural, com seus ranços corporativos e políticopartidários, com modelos de gestão personalistas e hierarquicamente verticalizadas, deve dar lugar a novas formas institucionais e gerenciais, que sejam capazes de incorporar o discurso que fazem sobre democratização e busca de bem-estar e bem viver das populações rurais. Insistimos, aqui, que nem a crítica nem a proposta de 
uma nova extensão rural são novas, mas a sua institucionalização e hegemonia estão longe de serem uma verdade inconteste.

Este novo enfoque requer outro tipo de profissionalismo, em todos os níveis das instituições, centrado em uma práxis que respeite os direitos de cidadania na gestão interna e, a partir daí, possa fortalecer iniciativas de ação extensionista comprometidas com os beneficiários, que respeitem os diferentes sistemas culturais, contribuam para melhorar os patamares de sustentabilidade ambiental dos agroecossistemas e contribuam para a produção de alimentos sadios, com melhor qualidade biológica, e acessíveis ao conjunto da população. Ou seja, produção de alimentos ecológicos que sejam comercializados através de outros circuitos que não aqueles das Cadeias Agroalimentares Convencionais.

Neste sentido, reafirmamos que desde 1998, estamos propondo a adoção da Extensão Rural Agroecológica como um enfoque novo para o extensionismo, pois ela se diferencia da extensão rural convencional, por tratar-se de:

\begin{abstract}
[...] um processo de intervenção de caráter educativo e transformador, baseado em metodologias de investigação-ação participante que permitam o desenvolvimento de uma prática social mediante a qual os sujeitos do processo buscam a construção e sistematização de conhecimentos que os leve a incidir conscientemente sobre a realidade, com o objetivo de alcançar um modelo de desenvolvimento socialmente equitativo e ambientalmente sustentável, adotando os princípios teóricos da Agroecologia como critério para o desenvolvimento e seleção das soluções mais adequadas e compatíveis com as condições específicas de cada agroecossistema e do sistema cultural das pessoas implicadas em seu manejo (CAPORAL, 1998).
\end{abstract}

Este é um conceito mais amplo que aquele da extensão difusionista, pois inclui a necessidade de uma práxis que deve ser distinta da convencional e exige a necessidade de considerar e incorporar aos processos de planejamento participativo os diferentes conhecimentos e estruturas de poder que influem nos processos de desenvolvimento rural e das agriculturas mais sustentáveis. Ademais, recomenda que o manejo dos recursos naturais e a adoção de opções tecnológicas sejam entendidos no marco de um processo de natureza construtivista, o que implica investigação, aprendizagem e ação e que, portanto, tem que ser respeitoso para com as pessoas, suas condições objetivas, seus conhecimentos, interesses e necessidades. Isto é, trata-se de uma práxis que respeita os sujeitos sociais envolvidos e que pode conduzir a um modelo de decisão e ação que contempla o caráter histórico e os aspectos políticos do desenvolvimento rural.

A adoção de tal conceito, pode também contribuir para fortalecer os processos de resistência que caracterizam as lutas históricas dos agricultores familiares camponeses, ante as tendências gerais e ameaças do desenvolvimento capitalista no campo. Isto leva a considerar a necessidade de adoção de estratégias diferenciadas, que incluem: a) a obrigatória imersão do agente de ATER, junto às comunidades; b) a adoção de metodologias participativas; c) a valorização do conhecimento local; d) entender a participação como direito de cidadania que gere empoderamento para os atores locais; e) adotar processos educativos (não persuasivos) capazes de contribuir para a emancipação dos sujeitos envolvidos; e f) contribuir na sistematização das experiências como forma de aprendizagem.

A ação da extensão rural em apoio a estratégias de desenvolvimento local e à transição em direção a estilos de agriculturas mais sustentáveis precisa partir do entendimento da agricultura como um processo permanente de aprendizagem e 
aplicação prática, reconhecendo que os agroecossistemas são o resultado de intervenções humanas e que, portanto, se constroem de diferentes formas, dado que os discursos sobre a natureza e as práticas agrícolas de diferentes grupos sociais estão afetados pela cultura, pela história, pela economia, pela tecnologia, pela ciência, assim como pelos mitos, crenças e conhecimentos locais que influenciam na relação entre natureza e cultura.

Este papel da Extensão Rural Agroecológica, sustentado pelos princípios da Agroecologia, pode ser decisivo para o apoio a processos de transição agroecológica que vimos antes.

\section{CONSIDERAÇÕES FINAIS}

Por fim, cabe enfatizar alguns pontos que se procurou mostrar neste texto. Por um lado, que a transição agroecológica é um processo ecológico e social que requer uma metodologia adequada, até porque não se trata apenas de ecologizar ou esverdear a produção agropecuária, florestal, etc, mas se trata de transformar positivamente os sistemas agroalimentares na direção da segurança e da soberania alimentar, assim como na direção de mais sustentabilidade socioambiental. Por outro lado, cabe destacar, também, que a transição não pode subordinar-se a nichos de mercado ou a processos de certificação, até porque, no limite, a utopia realizável da Agroecologia e da busca pela soberania alimentar é produzir alimentos sadios para todos, com menos danos ao meio ambiente e de forma a manter a base de recursos ambientais necessários para as futuras gerações.

Assim, a transição agroecológica não pode ser confundida com a simples conversão para sistemas orgânicos baseados apenas na substituição de insumos. Aliás, a realidade empírica tem demonstrado que estão sendo impulsionadas práticas de extensão convencional-difusionista que agora simplesmente trocaram o pacote da Revolução Verde pelo Pacote Orgânico, mantendo o mesmo modelo de educação bancária e de persuasão denunciado na década de 1960 do século passado por Paulo Freire (1983). A diferença é que agora a persuasão é para que agricultores adotem a agricultura orgânica.

Por fim, cabe ressaltar que o apoio a estes processos de transição não pode vir de uma extensão rural convencional, senão que requer um novo enfoque extensionista como aquele que definimos como Extensão Rural Agroecológica. O agente de extensão deverá atuar como um facilitador dos processos que devem ocorrer em cada uma das dimensões da transição que vimos acima.

\section{REFERÊNCIAS}

CALLE COLLADO, Á.; GALLAR, D. Agroecología Política: transición social y campesinado. In: VIII CONGRESSO LATINOAMERICANO DE SOCIOLOGÍA RURAL, 7., 2010, Porto de Galinhas. Anais... Porto de Galinhas, Pernambuco, 2010. $23 p$.

CALLE COLLADO, Á.; GALLAR, D.; CANDÓN, J. Agroecología Política: la transición social hacia sistemas agroalimentarios sustentables. Revista de Economía Crítica, n. 16, p. 244-277, jul./dez. 2013.

CAPORAL, F. R. La extensión agraria del sector público ante los desafíos del desarrollo sostenible: el caso de Rio Grande do Sul, Brasil. 1998. 517f. (Tese de Doutorado) - Programa de Doctorado en Agroecología, Campesinado e Historia, ISEC-ETSIAN, Universidad de Córdoba, España, 1998. 
CAPORAL, F. R. Agroecologia: uma nova ciência para apoiar a transição para agriculturas mais sustentáveis. In: FALEIRO, F. G.; FATIAS NETO, A. L. (Ed. Tec.) SAVANAS: Desafios e estratégias para o equilíbrio entre sociedade, agronegócio e recursos naturais. Planaltina-DF: EMBRAPA Cerrados, 2008. p. 895-929.

CAPORAL, F. R. Em defesa de um Plano Nacional de Transição Agroecológica: compromisso com as atuais e nosso legado para as futuras gerações. In: SAUER, S.; BALESTRO, M. V. (Orgs.) Agroecologia: os desafios da transição agroecológica. São Paulo: Expressão Popular, 2009. p. 267-311.

COSTABEBER, J. A.; CAPORAL, F. R.; WIZNIEWSKY, J. G. O conceito de Transição Agroecológica: contribuições para o redesenho de agroecossistemas em bases sustentáveis. In: COSTA GOMES, J. C.; ASSIS, W. S. Agroecologia: princípios e reflexões conceituais. Brasília-DF: EMBRAPA, 2013. p.145-180.

FREIRE, P. Extensão ou comunicação? Rio de Janeiro: Paz e Terra, 1983.

GLIESSMAN, S. Agroecologia: processos ecológicos em agricultura sustentável. Porto Alegre: Editora da UFRGS, 2000.

GLIESSMAN, S. Agroecology: a global movement for food security and sovereignty. In: Agroecology for Food Security and Nutrition. In: Proceedings of the FAO International Symposium. p.18-19, sep. 2014, Rome, Italy: FAO, 2015.

GLIESSMAN, S. Transforming food systems with agroecology. (Editorial). Agroecology and Sustainable Food Systems, v. 40, n. 3, p. 187-189, 2016.

GRAZIANO DA SILVA, J. A modernização dolorosa: estrutura agrária, fronteira agrícola e trabalhadores rurais no Brasil. Rio de Janeiro: Zahar. 1982.

OTERO, J.; SELIS, D. H. Educar, concientizar, transferir, dialogar... ¿qué es y para qué sirve la extenisón rural? Extensão Rural, Santa Maria, v.26, n.1, p.7-25, jan./mar. 2019. Disponível em: https://doi.org/10.5902/2318179635089. Acesso em: 08 jul. 2020.

SARANDÓN, S. J. La agricultura como actividad transformadora del ambiente. El impacto de la agricultura intensiva de la Revolución Verde. In: SARANDÓN, S. J. (Ed.). Agroecología: el camino hacia una agricultura sustentable. Buenos Aires: Ediciones Científicas Americanas, 2002. p. 23-47.

SEVILLA GUZMÁN, E. El marco teórico de la Agroecología. In: Materiales de Trabajo del Ciclo de Cursos y Seminarios sobre Agroecología y Desarrollo Sostenible en América Latina y Europa. Módulo I - Agroecología y Conocimiento Local (La Rábida, 16 a 20 de enero de 1995). Huelva, La Rábida: Universidad Internacional de Andalucía, 1995. p. 3-28.

SEVILLA GUZMÁN, E.; SOLER MONTIEL, M.; GALLAR, D.; VARA-SÁNCHEZ, I.; CALLE, A. Canales cortos de comercialización alimentaria en Andalucía. Sevilla: Fundación Pública Andaluza Centro de Estudios Andaluces, Consejería de la Presidencia e Igualdad, Junta de Andalucía, 2012. 